\title{
Double trouble: a rare case of bilateral ectopic pregnancy following intracytoplasmic sperm injection
}

\section{Tejal Poddar*, Pooja Nadkarni Singh, Purnima Nadkarni}

21st Century Fertility Centre, Surat, Gujarat, India

Received: 01 March 2016

Accepted: 30 March 2016

\section{*Correspondence:}

Dr. Tejal Poddar,

E-mail: tejalpoddar@gmail.com

Copyright: (C) the author(s), publisher and licensee Medip Academy. This is an open-access article distributed under the terms of the Creative Commons Attribution Non-Commercial License, which permits unrestricted non-commercial use, distribution, and reproduction in any medium, provided the original work is properly cited.

\section{ABSTRACT}

Bilateral tubal pregnancy is a rare clinical condition which occurs in only 1 per 200,000 pregnancies. The common risk factors are assisted reproductive technique, pelvic infection and tubal surgery. Such unusual cases may go undiagnosed and the consequences can be devastating. We present one such rare case of bilateral tubal pregnancy in a woman who underwent IVF treatment. A 41-year-old woman who had secondary infertility was admitted with ultrasonography suggestive of ectopic pregnancy. The couple had opted for ovum donation with ICSI due to low ovarian reserve. In the next ICSI cycle, three 4-cell grade A (excellent grade) transferred 72 hours after oocyte retrieval. Two weeks after ET, the patient's first $\beta$-hCG level was $345 \mathrm{mIU} / \mathrm{ml}$. Following which second $\beta$-hCG was $2177 \mathrm{mlU} / \mathrm{ml}$ on day 20 after ET. Upon ultrasound examination no intrauterine pregnancy could be visualized. Approximately 7-8 mm sized unruptured ectopic gestation sac was visualized in right adnexa. She did not experience any vaginal bleeding or pain and was haemodynamically stable. Laparoscopy was performed and it revealed bilateral ectopic pregnancy. Bilateral salpingectomy was performed.

Keywords: Bilateral ectopic, ICSI pregnancy, bilateral salpingectomy

\section{INTRODUCTION}

The implantation of trophoblastic tissue outside the uterine cavity occurs in $1.5 \%$ to $2 \%$ of all pregnancies. In more than $90 \%$ of cases, this occurs in the fallopian tubes, and 8 per 10 cases are located in the ampullar region. ${ }^{1}$ According to the reports the frequency of ectopic pregnancies has grown in the last 30 years. ${ }^{2}$ But bilateral tubal pregnancy is a rare clinical condition which occurs in only 1 per 200,000 pregnancies. $^{3}$ The commonly associated risk factors are assisted reproductive techniques, pelvic infection and previous tubal surgery.

While most physicians are familiar with the typical presentations of ectopic pregnancy and manage the cases well, unusual cases may go undiagnosed and the consequences can be devastating.
We present one such rare case of bilateral tubal pregnancy in a woman who underwent IVF treatment, in whom three embryos were transferred.

\section{CASE REPORT}

A 41-year-old woman married for 20 years came with secondary infertility having two previous normal deliveries 18 years and 16 years back. The patient had regular menstrual cycles with no history of pelvic inflammatory disease. Bilateral tubal patency was revealed on hysterosalpingography and hysteroscopy was normal. TB -PCR was also negative.

She had been treated with three cycles of controlled ovarian hyper-stimulation with IUI at another fertility centre, which she failed. The couple then opted for ovum donation with ICSI due to low ovarian reserve with AMH of $<0.3$. Ovum donor was selected who was 23 years of 
age with one previous normal delivery. She was treated with the standard antagonist protocol. Ten oocytes were retrieved, of which six were fertilized and cleaved.

In the ICSI cycle in the same month, with endometrial thickness of $9.6 \mathrm{~mm}$, three embryos were transferred 72 hours after ICSI. A soft embryo transfer (ET) catheter (Sydney, IVF, Australia) was used to transfer the embryos, which was done without complications. The luteal phase was supported with vaginal progesterone, $400 \mathrm{mg}$ twice daily until the day of the $\beta$-hCG assay. Two weeks after ET, the patient's first $\beta$-hCG level was $345 \mathrm{mIU} / \mathrm{ml}$. Following which second $\beta$-hCG was 2177 $\mathrm{mlU} / \mathrm{ml}$ on day 20 after ET.

Upon ultrasound examination no intrauterine pregnancy could be visualized. Endometrial thickness was 7-8 mm. Both ovaries were well visualized. Approximately 7-8 mm sized unruptured ectopic gestation sac was visualized in right adnexa just inferior to right ovary. There was no evidence of any free fluid in the pelvis. She did not experience any vaginal bleeding or pain. Upon admission, she had blood pressure of $126 / 80 \mathrm{mmHg}$ and a heart rate of 80 beats per minute.

Laparoscopy was performed, which revealed a $2 \mathrm{~cm}$ ruptured right ampullary ectopic pregnancy. A right sided salpingectomy was done. Inspection of the left tube showed a bulging area in the ampullary region with ruptured left tubal ectopic pregnancy as well. Left sided salpingectomy was also done. Left and right ovaries were intact macroscopically. Endometrial curettage was done which revealed desidual reactionary material. Pathology confirmed placental villi in the right and left tubes. The patient was discharged home on the third day post operatively, in stable condition.
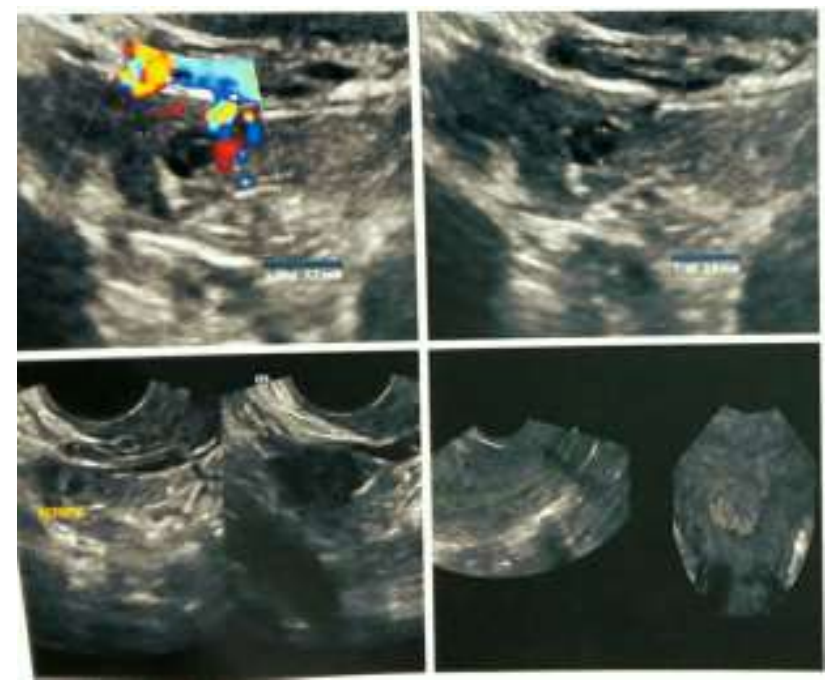

Figure 1: Ultrasound image demonstrating the presence of a complex mass in the right adnexa with vascularity present and the absence of an intrauterine pregnancy.
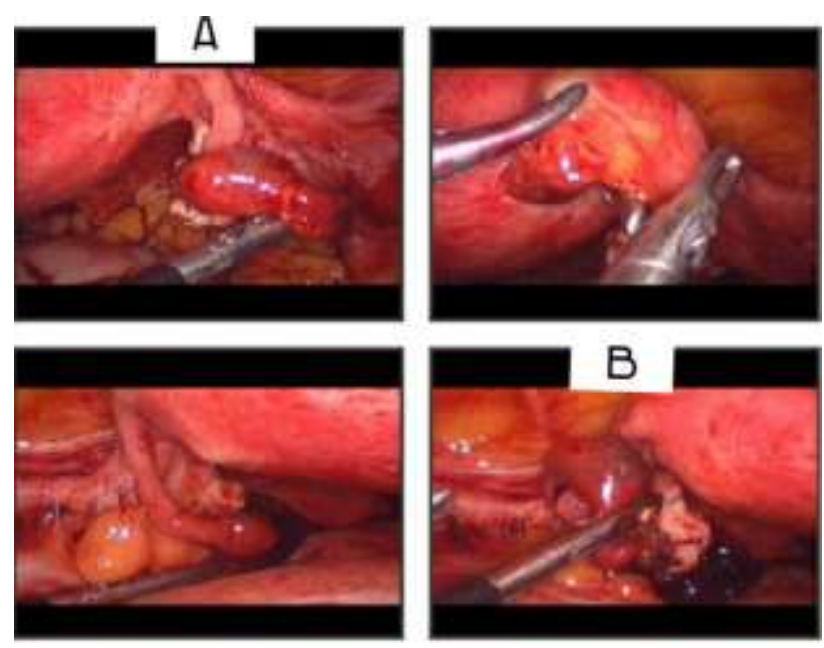

Figure 2: Laparoscopic images of bilateral tubal pregnancy. A; right sided tubal ectopic pregnancy, B; left sided tubal ectopic pregnancy.

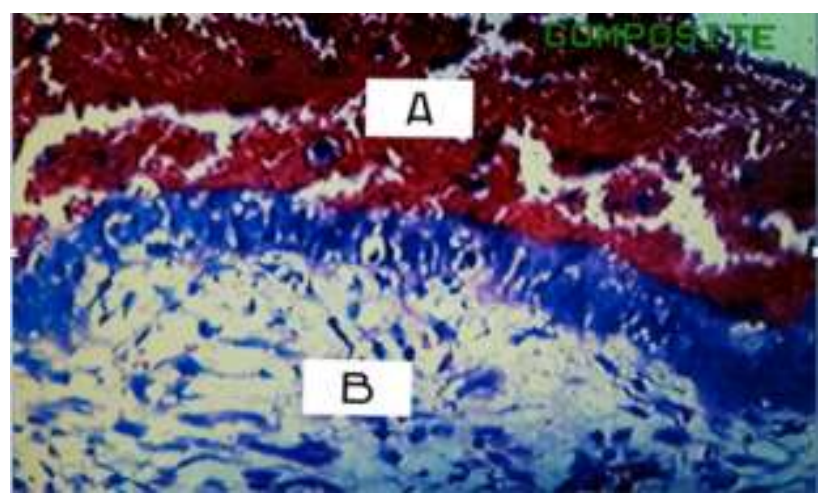

Figure 3: Haematoxylin and eosin stain x200 Section of the left fallopian tube showing chorionic villi. A; chorionic villi, B; fallopian tube wall.

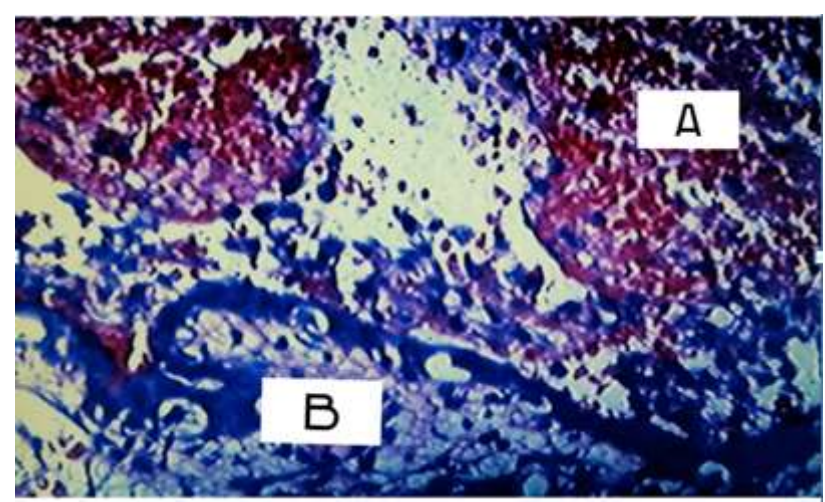

Figure 4: Haematoxylin and eosin stain x200 Section of the right fallopian tube showing chorionic villi. A; chorionic villi, B; fallopian tube wall.

\section{DISCUSSION}

In literature there were almost 50 cases of bilateral ectopic pregnancy since 1997, and almost $50 \%$ of them were reported as spontaneous bilateral ectopic pregnancies. ${ }^{1}$ The first pregnancy obtained with IVF by Steptoe et al. was ectopic, in a patient with history of 
tubal factor infertility. ${ }^{4}$ The first case of a bilateral tubal ectopic pregnancy after IVF-ET was published in 1983, but spontaneous bilateral tubal pregnancy was reported in $1918^{5,6}$

The likelihood of bilateral tubal pregnancy is not only due to embryos reaching the tubes, but may be because of an additional pathology that prevents their movement back to the uterus. This mechanism may be the result of tubo-peritoneal disease or the embryo itself. Tuboperitoneal disease can interfere with tubal motility. ${ }^{7}$ Blastocyst transfer has a higher implantation rate when compared to the cleavage stage transfer. ${ }^{8}$ This would imply that the blastocyst which reaches the tube may have a higher chance of implantation. A significant difference in the ectopic pregnancy rate was found between single and double transfers when frozen blastocyst transfers were performed. ${ }^{9}$ However, Milki et al found no differences in ectopic pregnancy rates with day 3 versus day 5 embryo transfers. ${ }^{10}$

There are three theories to explain the origin of a bilateral ectopic pregnancy after IVF. The first theory is that the embryos might be directly injected into the tubes because of a poor transfer technique. The second hypothesis is that, the embryos transferred to the endometrial cavity could regressively migrate back to the tubes as a consequence of endometrial secretions that push them in that direction. The third is the "spray effect theory" produced during embryo transfer; when emptying the hypodermic syringe, the embryos could possibly "be pushed" toward the tubal portions.

\section{CONCLUSION}

A patient who has had one ectopic pregnancy is at risk of having another - not just in the future, but also at the same time. Hence early detection of a rising b-HCG would be a valuable tool in detection of these unusual cases and would assist in early diagnosis and prompt management. The diagnosis of ectopic pregnancy should always be considered in patients undergoing IVF-ET, because of its increased incidence compared to natural conception. Although the incidence of a bilateral ectopic pregnancy is not very high, and it may also occur after spontaneous pregnancy, both adnexa should be examined when diagnosis of an ectopic pregnancy is made.

Funding: No funding sources

Conflict of interest: None declared

Ethical approval: Not required

\section{REFERENCES}

1. De Los Ríos JF, Castaneda JD, Miryam A. Bilateral ectopic pregnancy. J Minim Invasive Gynecol. 2007;14(4):419-27.

2. Stabile I, Grudzinskas JG. Ectopic pregnancy: a review of incidence, etiology and diagnostic aspects. Obstet Gynecol Surv. 1990;45(6):335-47.

3. Jonler M, Rasmussen KL, Lundorff P. Coexistence of bilateral tubal and intrauterine pregnancy. Acta Obstet Gynecol Scand. 1995;74:750-2.

4. Steptoe PC, Edwards RG. Reimplantation of a human embryo with subsequent tubal pregnancy. Lancet. 1976;1(7965):880-2.

5. Trotnow S, Al-Hasani S, Hünlich T, Schill WB. Bilateral tubal pregnancy following in vitro fertilization and embryo transfer. Arch Gynecol. 1983;234(1):75-8.

6. Hewitt J, Martin R, Steptoe PC, Rowland GF, Webster J. Bilateral tubal ectopic pregnancy following in-vitro fertilization and embryo replacement. Case report. Br J Obstet Gynaecol. 1985;92(8):850-2.

7. Herman A, Ron-El R, Golan A, Weinraub Z, Bukovsky I, Caspi E. The role of tubal pathology and other parametersin ectopic pregnancies occurring in in vitro fertilization and embryo transfer. Fertil Steril. 1990;54:864-8.

8. Schwarzler P, Zech H, Auer M. Pregnancy outcome after blastocyst transfer as compared to early cleavage stage embryo transfer. Hum Reprod. 2004;19:2097-102.

9. Yanaihara A, Yorimitsu T, Motoyama H, Ohara M, Kawamura T. Clinical outcome of frozen blastocyst transfer; single vs. double transfer. J Assist Reprod Genet. 2008;25:531-4.

10. Milki AA, Jun SH. Ectopic pregnancy rates with day 3 versus day 5 embryo transfer: a retrospective analysis. BMC Pregnancy Childbirth. 2003;3:7.

Cite this article as: Poddar T, Nadkarni PS, Nadkarni P. Double trouble: a rare case of bilateral ectopic pregnancy following intracytoplasmic sperm injection. Int J Reprod Contracept Obstet Gynecol 2016;5:1657-9. 